\title{
RETINAL ANGIOMATOUS PROLIFERATION
}

\section{A Quantitative Analysis of the Fundoscopic Features of the Fellow Eye}

\author{
JOÃO PEDRO MARQUES, MD, MSc, ${ }^{*} \dagger$ INÊS LAÍNS, MD, MSc, ${ }^{*}+$ MIGUEL ÂNGELO COSTA, MSc, $\dagger$ \\ ISABEL PIRES, MD, $* \dagger+$ MARIA DA LUZ CACHULO, MD, $* \dagger \neq$ JOÃO FIGUEIRA, MD, $* \dagger+$ \\ RUFINO SILVA, MD, PHD*††
}

Purpose: To quantitatively analyze and compare the fundoscopic features between fellow eyes of retinal angiomatous proliferation and typical exudative age-related macular degeneration and to identify possible predictors of neovascularization.

Methods: Retrospective case-control study. Seventy-nine fellow eyes of unilateral retinal angiomatous proliferation $(n=40)$ and typical exudative age-related macular degeneration $(n=39)$ were included. Fundoscopic features of the fellow eyes were assessed using digital color fundus photographs taken at the time of diagnosis of neovascularization in the first affected eye. Grading was performed by two independent graders using RetmarkerAMD, a computer-assisted grading software based on the International Classification and Grading System for age-related macular degeneration.

Results: Baseline total number and area (square micrometers) of drusen in the central $1,000,3,000$, and $6,000 \mu \mathrm{m}$ were considerably inferior in the fellow eyes of retinal angiomatous proliferation, with statistically significant differences $(P<0.05)$ observed in virtually every location $(1,000,3,000$, and $6,000 \mu \mathrm{m})$. A soft drusen $(\geq 125 \mu \mathrm{m})$ area $>510,196 \mu \mathrm{m}^{2}$ in the central $6,000 \mu \mathrm{m}$ was associated with an increased risk of neovascularization (hazard ratio, 4.35; 95\% confidence interval [1.56-12.15]; $P=0.005)$.

Conclusion: Baseline fundoscopic features of the fellow eye differ significantly between retinal angiomatous proliferation and typical exudative age-related macular degeneration. A large area $\left(>510,196 \mu \mathrm{m}^{2}\right)$ of soft drusen in the central $6,000 \mu \mathrm{m}$ confers a significantly higher risk of neovascularization and should be considered as a phenotypic risk factor.

RETINA 35:1985-1991, 2015

$\mathrm{B}$ ased on the first description by Hartnett et $\mathrm{al}^{1}$ in 1992, Yannuzzi et $\mathrm{al}^{2}$ introduced the term retinal angiomatous proliferation (RAP) to describe a distinct phenotype of exudative age-related macular degeneration

From the *Department of Ophthalmology, Centro Hospitalar e Universitário de Coimbra (CHUC), Coimbra, Portugal; †Association for Innovation and Biomedical Research on Light and Image (AIBILI), Coimbra, Portugal; and $\ddagger$ Faculty of Medicine, University of Coimbra (FMUC), Coimbra, Portugal.

None of the authors have any financial/conflicting interests to disclose.

There was no founding from National Institutes of Health $(\mathrm{NIH})$, Wellcome Trust, Howard Hughes Medical Institute (HHMI), or others.

Reprint requests: João Pedro Marques, MD, MSc, Department of Ophthalmology, Centro Hospitalar e Universitário de Coimbra, Praceta Prof. Mota Pinto, 3049 Coimbra, Portugal; e-mail: marquesjoaopedro@ gmail.com
(eAMD), in which the neovascular complex originates deeply in the retina. ${ }^{3,4}$ Retinal angiomatous proliferation has also been labeled Type 3 neovascularization and the two terms have been used interchangeably. ${ }^{5,6}$

Although the prevalence of the disease is low in asians ${ }^{7,8}$ and blacks, ${ }^{5}$ RAP is estimated to represent $12 \%$ to $20 \%$ of the wet age-related macular degeneration (AMD) cases in white populations, ${ }^{2,6,9-11}$ where it poses a substantial burden.

It is currently well established that RAP and typical eAMD present distinct clinical and epidemiologic features (age, sex, among others ${ }^{12,13}$ ), most of them likely due to genetic differences still not completely understood. $^{14}$ Retinal angiomatous proliferation has been coined a bilaterally aggressive disease with predictable symmetry. ${ }^{5}$ Although definite proof on the form of 
a prospective randomized clinical trial is still lacking, the vasogenic potential associated with RAP has been highlighted by several study groups, ${ }^{9,15,16}$ reporting annual and cumulative rates of neovascularization in fellow eyes far exceeding the typical forms of eAMD. Considering this alleged aggressiveness, the identification of pre-exudative changes in the fellow eye, potentially associated with a higher risk of neovascularization, is of the utmost importance.

Fundoscopic features such as drusen characteristics or the presence of pigmentary changes are considered important ocular risk factors for typical eAMD. ${ }^{17-21}$ Because of its relevance in clinical practice, the AREDS group ${ }^{22}$ created a simplified point scoring system that provides baseline risk stratification, allows tracking of progression, and defines surrogate outcomes for progression by estimating the 5-year risk of developing advanced AMD. Despite the well-documented presence of soft drusen and pigmentary changes in eyes with $\mathrm{RAP}^{2,4,16,23-27}$ an objective and rigorous analysis of their characteristics and an assessment of their possible influence in the development of neovascularization in the fellow eye is lacking. The characterization of phenotypic risk factors in fellow eyes of RAP could be of practical clinical value, since it would alert the eye-care providers for the possibility of a more aggressive scenario. The purpose of this study was to assess and compare the fundoscopic changes in fellow eyes of RAP and typical eAMD and to identify possible predictors of neovascularization.

\section{Methods}

Retrospective case-control study. Enrolled patients were consecutively selected from a database initially created as part of a prospective observational study (Characterization of Early Markers of Choroidal Neovascularization - CNV Markers, ${ }^{28}$ NCT00801541) designed to identify morphological and/or functional predictors of neovascularization in unaffected fellow eyes of exudative AMD. At enrollment, every included subject was asked to sign an informed consent form in accordance with the Declaration of Helsinki, where they agreed that their clinical data could be included in scientific studies. Bilateral color fundus digital photographs (CFP), spectral domain optical coherence tomography, fluorescein angiography, and indocyanine green angiography were performed at baseline in every patient, along with a complete ophthalmological examination. During follow-up, all patients had periodical visits, where the ophthalmological examination and optical coherence tomography were always repeated. If the study eye (fellow eye) developed neovascularization, its incidence, time of occurrence, and phenotype were registered. All the diagnoses were confirmed by two of three senior retina specialists (R.S., M.d.L.C., or J.F.), after reviewing the ocular changes using multimodal retinal imaging (CFP, spectral domain optical coherence tomography, fluorescein angiography, and indocyanine green angiography). The criteria used for RAP diagnosis have already been described by our group. ${ }^{29,30}$

For the purposes of this study, we identified and selected consecutive patients with unilateral RAP (Group 1) from the above-mentioned database. The same database was also used to identify consecutive patients with unilateral typical eAMD, to create the control group (Group 2). The following eligibility criteria were considered for patient selection in both groups: 1) any race and either sex, 2) age $\geq 50$ years, 3 ) diagnosis of unilateral typical eAMD or RAP at baseline, and 4) fellow eye (study eye) without any signs of neovascularization at enrollment. Patients with ophthalmologic comorbidities (other than agerelated maculopathy) likely to jeopardize the grading of the color fundus pictures were excluded from the study.

\section{Color Fundus Photograph Grading}

The mydriatic CFP of the unaffected fellow eye used for grading were obtained at the time of diagnosis of neovascularization in the non-study eye using a Zeiss FF450 Fundus Camera equipped with a Nikon highresolution camera. All the fundus images were centered at the fovea, with a $30^{\circ}$ field of view and a $1,594 \times$ 1,326 pixel resolution (50\% of maximum resolution) was used for grading purposes. Grading took place at the Coimbra Ophthalmology Reading Center by two independent graders certified by this institution and was performed using RetmarkerAMD (Retmarker SA, Coimbra, Portugal), a computer-assisted grading software developed according to the guidelines of the International Classification and Grading System for AMD. ${ }^{31}$ Both free forms and predefined circles $(63,125,175$, 250 , and $500 \mu \mathrm{m})$ are available for grading and allow for an accurate quantification of fundus features in digital CFP, including drusen, pigmentary changes, geographic atrophy (GA), or exudative lesions (Figure 1). In addition to a categorical depiction of variables, such as the number $(0,1-9,0-19, \geq 20)$ and area occupied by drusen $(<1 \%,<10 \%,<25 \%,<50 \%, \geq 50 \%)$, the software allows its quantification as continuous variables, thus reflecting the real (absolute) number and area of drusen. ${ }^{21}$ The grading results are readily accessible on screen and can be easily exported as a Microsoft Excel file for further statistical analysis. 

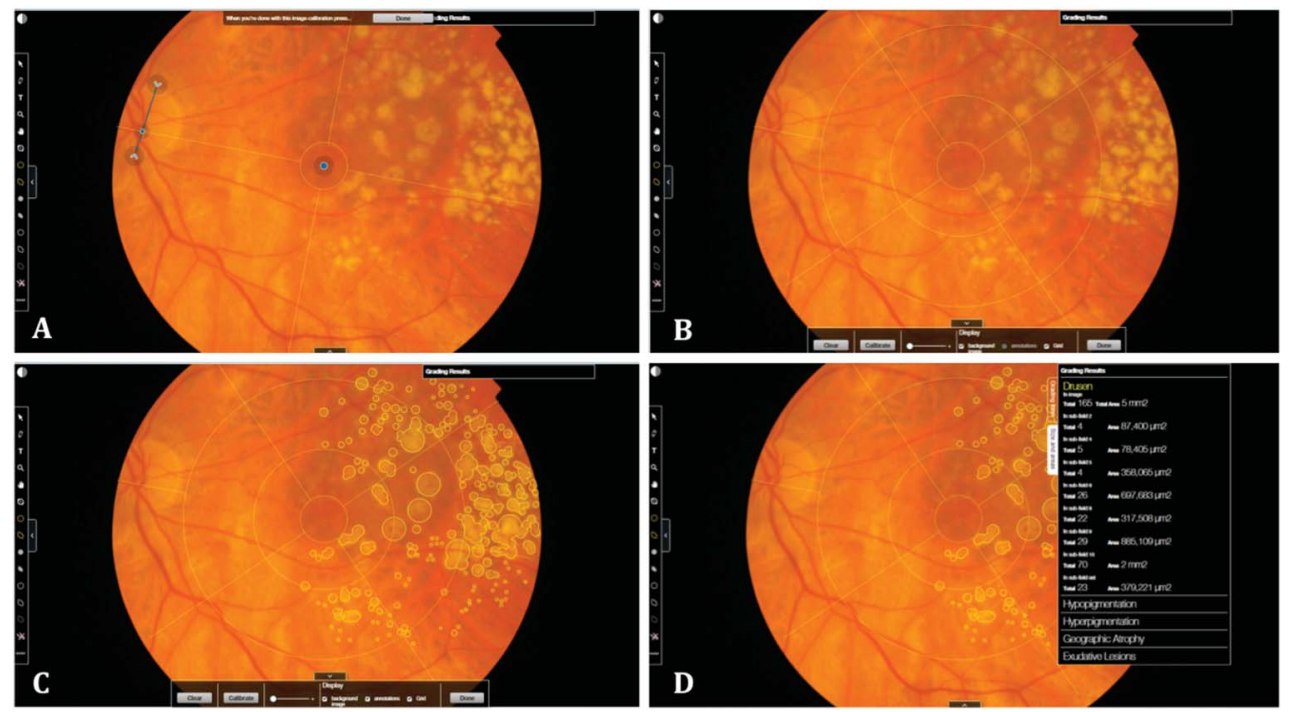

Fig. 1. Real-time grading using RetmarkerAMD (Critical Health $\mathrm{SA}$ ) in one of the included subjects of the RAP group. A. Calibration is achieved after manually identifying the fovea and establishing the optic disk diameter (blue dot and arrow, respectively). The software then generates a reference grid (B) according to the International Classification and Grading System for AMD. ${ }^{31}$ C. Both free forms and predefined circles $(63,125,175,250$, and $500 \mu \mathrm{m}$ ) can be used for quantifying fundus features in digital color fundus photographs, including drusen, pigmentary changes, GA, or exudative lesions. D. The grading results are readily available on screen and can be easily exported as a Microsoft Excel file for further statistical analysis.

\section{Statistical Analysis}

Distribution of the several parameters was assessed with Mann-Whitney $U$ tests, and influence of age as a covariate was explored with factorial analyses of variance.

Receiver operating characteristic curves and Cox proportional hazard models were used for determining cutoffs and evaluating conversion risks, respectively. Alpha was defined at 0.05 and all analyses were performed with Stata 12.1 for Windows (StataCorp LP, TX).

\section{Results}

\section{Study Population}

Seventy-nine fellow eyes of RAP (Group 1, n = 40) and unilateral typical eAMD (Group 2, n = 39) were included. All the included subjects were white. The demographic data of both groups are expressed in Table 1. Patients included in Group 1 were significantly older than patients included in Group $2(P<$ $0.001)$. In the RAP group, $40 \%(n=16)$ of the fellow eyes developed neovascularization during follow-up (mean \pm SD: $33.50 \pm 21.10$ months). The average time to conversion of the fellow eye was $20.56 \pm 10.84$ months. The cumulative incidence of neovascularization was $12.5 \%$ at 1 year, $29.6 \%$ at 2 years, $39.9 \%$ at 3 years, and $47.6 \%$ at 4 years. In the eAMD group (Group 2), conversion to neovascularization occurred in $48.7 \%(n=19)$ of the fellow eyes, during a followup period of $89.54 \pm 25.65$ months. The average time to conversion was $53.32 \pm 25.65$ months. The cumulative incidence of neovascularization was $2.6 \%$ at 1 year, $13.1 \%$ at 2 years, $21.9 \%$ at 3 years, $31.6 \%$ at 4 years, $34.9 \%$ at 5 years, and $62.4 \%$ at 10 years.

\section{Analysis of the Fundoscopic Changes}

Considering the purposes of this analysis, we initially performed a comparison between the baseline CFP grading results of the 2 groups (Table 2). The total number and area (square micrometers) of drusen in the central $1,000,3,000$, and $6,000 \mu \mathrm{m}$ were considerably inferior in the fellow eyes of RAP, with statistically significant differences observed in virtually every location $(1,000,3,000$, and 6,000 $\mu \mathrm{m})$. When considering only the total number and area of soft drusen ( $\geq 125 \mu \mathrm{m}$ ), there were no statistically significant differences between groups in the central 1,000 $\mu \mathrm{m}(P=0.187$ and $P=0.118$, respectively) or $3,000 \mu \mathrm{m}(P=0.124$ and

Table 1. Demographic Characteristics of the Study Population

\begin{tabular}{lccr}
\hline & Group 1-RAP & Group 2-Typical eAMD & $P$ \\
\hline $\mathrm{n}$ & 40 & $17(43.6 \%) / 22(56.4 \%)$ & \\
$\mathrm{RE} / \mathrm{LE}(\%)$ & $18(45 \%) / 22(55 \%)$ & $15(38.5 \%) / 24(61.5 \%)$ & 0.900 \\
Male/female (\%) & $15(37.5 \%) / 25(62.5 \%)$ & $70.87 \pm 5.74$ & 0.952 \\
Age (mean \pm SD) & $77.50 \pm 6.88$ & $<0.001^{*}$ \\
\hline
\end{tabular}

RAP, retinal angiomatous proliferation; eAMD, exudative age-related macular degeneration; RE, right eye, LE, left eye; SD, Standard deviation.

${ }^{\star} P<0.05$. 
Table 2. Grading Results Concerning the Total Number and Area of Drusen in the Central 1,000, 3,000, and 6,000 $\mu \mathrm{m}$, Both for the RAP and Typical eAMD Groups

\begin{tabular}{|c|c|c|c|c|c|}
\hline & \multicolumn{2}{|c|}{ RAP } & \multicolumn{2}{|c|}{ Typical eAMD } & \multirow[b]{2}{*}{$P$} \\
\hline & Mean & SD & Mean & SD & \\
\hline \multicolumn{6}{|l|}{ Central $1,000 \mu \mathrm{m}$} \\
\hline Total no. drusen & 6.40 & 7.19 & 12.74 & 12.23 & $0.014^{x}$ \\
\hline Total area of drusen $\left(\mu \mathrm{m}^{2}\right)$ & 41.28 & 73.47 & 89.62 & 103.89 & $0.009^{*}$ \\
\hline \multicolumn{6}{|l|}{ Central 3,000 $\mu \mathrm{m}$} \\
\hline Total no. drusen & 57.65 & 41.29 & 99.87 & 78.63 & $0.018^{\star}$ \\
\hline Total area of drusen $\left(\mu \mathrm{m}^{2}\right)$ & 477.68 & 496.38 & 775.49 & 685.07 & 0.052 \\
\hline \multicolumn{6}{|l|}{ Central 6,000 $\mu \mathrm{m}$} \\
\hline Total no. drusen & 126.85 & 95.25 & 251.59 & 204.98 & $0.005^{\star}$ \\
\hline Total area of drusen $\left(\mu \mathrm{m}^{2}\right)$ & 977.00 & 962.10 & $1,955.18$ & $1,858.00$ & $0.020^{*}$ \\
\hline
\end{tabular}

RAP, retinal angiomatous proliferation; eAMD, exudative age-related macular degeneration; no., number; SD, Standard deviation. ${ }^{*} P<0.05$.

$P=0.336$, respectively). However, in the central $6,000 \mu \mathrm{m}$, the total number of drusen $\geq 125 \mu \mathrm{m}$ was significantly smaller $(P=0.021)$ in the fellow eyes of RAP, although their area was not $(P=0.078)$.

Despite the significant age difference between groups, a factorial analysis of variance demonstrated that the difference in drusen number was not influenced by the older age of the patients with RAP. Afterward, to identify potential phenotypic risk factors for conversion, we compared the characteristics of fellow eyes of RAP that developed neovascularization $(\mathrm{n}=16)$ during follow-up, with those that did not $(n=24)$. This analysis revealed that the first presented a borderline significant $(P=0.053)$ superior total area of drusen $\geq 125 \mu \mathrm{m}$ in the central 6,000 $\mu \mathrm{m}$ (Figure 2). A receiver operating characteristic curve analysis was used to find the cutoff value that better predicts the advent of neovascularization. A total area of soft drusen $(\geq 125 \mu \mathrm{m})>510.196 \mu \mathrm{m}^{2}$ was shown to significantly increase the risk of neovascularization with $68.75 \%$ sensitivity and $70.83 \%$ specificity.

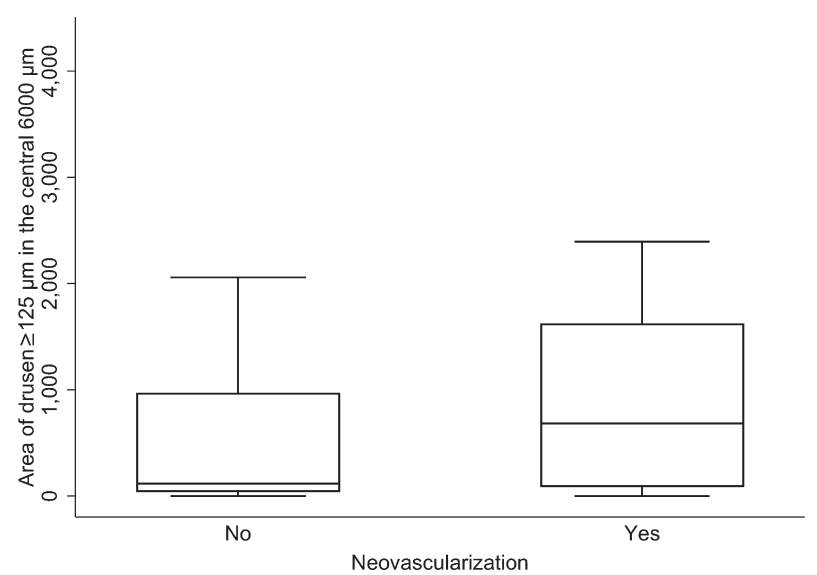

Fig. 2. Box plot showing the difference in the area of drusen $\geq 125 \mu \mathrm{m}$ in the central $6,000 \mu \mathrm{m}$ between fellow eyes of RAP that did and did not develop neovascularization $(P=0.053)$. Central bars indicate median values; boxes indicate interquartile ranges, and whiskers extend to the highest and lowest values.
The Cox regression analysis revealed an associated hazard ratio of $4.35(P=0.005 ; 95 \%$ confidence interval: 1.56-12.15).

Pigmentary changes (hypopigmentation or hyperpigmentation) were found in 13 fellow eyes of the RAP group (32.5\%) and in 8 fellow eyes of Group 2 $(20.5 \%)$. However, the observed differences did not reach statistical significance, regardless of location (central 1,000, 3,000, or $6,000 \mu \mathrm{m}$ ).

\section{Discussion}

In patients with RAP, the presence of small hemorrhages, soft drusen, and pigmentary changes is well documented, ${ }^{2,16,23-27}$ but an accurate analysis of the fundoscopic features of the fellow eyes was lacking. Using a precise and easily reproducible methodology, ${ }^{21,28}$ we analyzed and compared fundoscopic changes between two demographically similar populations of fellow eyes of RAP and typical eAMD. Although still not widely spread in clinical and/or research settings, the use of semiautomated image analysis systems represents a convenient and versatile way of grading fundus changes, significantly reducing the time and expense associated with manual grading. ${ }^{32}$

We found that the total number and area of drusen were significantly lower in fellow eyes of RAP, in almost every location (central 1,000, 3,000, and 6,000 $\mu \mathrm{m}$ ). When considering only drusen $\geq 125 \mu \mathrm{m}$, the difference between groups reached statistical significance for the total number of drusen in the central $6,000 \mu \mathrm{m}(P=0.0021)$, although not for their area $(P=0.078)$. The significance of these results was emphasized after excluding age as a possible confounding factor. Fujimura et $\mathrm{al}^{8}$ compared drusen area and characteristics of fundus autofluorescence (FAF) between fellow eyes of Japanese patients with polypoid choroidal vasculopathy $(\mathrm{PCV})(\mathrm{n}=95)$, typical 
eAMD ( $\mathrm{n}=64)$, and RAP ( $=4)$. Despite having found statistically significant differences between the PCV group and the typical eAMD group, the authors reported that it was not possible to adequately characterize the RAP group, due to the small number of subjects included. Another study in Asians, conducted by $\mathrm{Kim}$ et $\mathrm{al}^{24}$ compared the extent and density of drusen between eyes with RAP $(n=20)$ and typical eAMD $(n=24)$. The fellow eyes of these patients were also evaluated whenever bilateral neovascularization was not present. The authors found that the density of drusen in the macular area was significantly higher in fellow eyes of RAP $(n=10)$ than in fellow eyes of typical eAMD $(n=17){ }^{24}$ These findings are the exact opposite of ours. Aside from the ethnical differences between populations, the study of Kim et $\mathrm{al}^{24}$ has several important limitations that may have influenced the disparity of results. First of all, the authors analyzed a small number of fellow eyes and presented nonequivalent groups. Furthermore, the evaluation of drusen extent lacks accuracy, since patients were divided in groups: small extent $(<1 / 3$ of the fundus photograph), intermediate extent $(1 / 3-2 / 3$ of the fundus photograph), and large extent ( $>1 / 3$ of the fundus photograph). Therefore, only a mere estimation of the total area occupied by drusen was determined. Finally, in their study drusen density was evaluated only in the central 3,000 $\mu \mathrm{m}$, when the International Guidelines for classification and grading of $\mathrm{AMD}^{31}$ consider the central $6,000 \mu \mathrm{m}$. Our sample size along with the clear and precise methodology with which we evaluated the total number and area of drusen adds robustness to our analysis and reinforce the obtained results.

We believe that one possible explanation for the differences we found between drusen characteristics in fellow eyes of RAP and typical eAMD may be the frequent development of GA in eyes with RAP. It was previously thought that GA in RAP was secondary to the treatments used. ${ }^{33,34}$ However, in a recent study using FAF, McBain et $\mathrm{a}^{35}$ found high rates of GA in RAP, independently of treatment modalities (photodynamic therapy or antiangiogenic agents). This finding may constitute a consequence of the reduced choroidal perfusion and thickness in RAP, which may be associated with the high vasogenic potential observed in these patients. ${ }^{24,35,36}$ Since baseline evaluation of our patients did not include FAF, a precise determination of possible areas of GA in our population of fellow eyes could not be achieved and this constitutes a limitation of our study.

In our study, we have also looked at possible phenotypic risk factors associated with a higher rate of conversion. We found that a total area of soft drusen $(\geq 125 \mu \mathrm{m})>510.2 \mu \mathrm{m}^{2}$ in the central $6,000 \mu \mathrm{m}$ was associated with a higher risk of neovascularization (hazard ratio, 4.35; 95\% confidence interval [1.5612.15]; $P=0.005$ ) in fellow eyes of RAP. Although this result should be interpreted carefully, it constitutes a clinically relevant finding since it might allow identification of patients with a high probability of conversion at the time of neovascularization of the first affected eye, in a fast and easy way. Sawa et $\mathrm{al}^{16}$ evaluated the correlation between several determinants (age, sex, follow-up time, presence of soft drusen, and presence of reticular pseudodrusen [RPD]) and the development of RAP in fellow eyes. The authors concluded that a long follow-up and the presence of RPD were associated with conversion. ${ }^{16}$ In their analysis, they included soft drusen as a categorical variable (present/not present) and did not calculate its area and number. As previously reported, soft drusen are a common finding in $\operatorname{RAP}^{23,27}$ so it is totally justifiable that there was no correlation with conversion when the variable is assessed categorically. Several authors have postulated an association between RPD and advanced forms of AMD. ${ }^{37-40}$ Both Zweifel et $\mathrm{al}^{40}$ and Hogg et $\mathrm{al}^{37}$ demonstrated that CFP and red-free are poor means for the detection of RPD, and diagnosis is best achieved using infrared or FAF. Since baseline evaluation of our patients did not include either of these retinal imaging modalities, a quantitative evaluation of RPD could not be attained, thus representing a limitation of our study.

The presence of pigmentary changes has been identified as a risk factor for the development of CNV in patients with typical eAMD. ${ }^{20,22,41}$ Campa et $\mathrm{al}^{15}$ identified foci of hyperpigmentation in 29 (78.4\%) of the 37 fellow eyes of RAP in their study and suggested that these could constitute an important risk factor for the development of RAP since it was present in $90 \%$ of those who developed neovascularization. Although we found foci of hyperpigmentation in $1 / 3$ of patients in the RAP group and in $20 \%$ of patients in the eAMD group, the difference between groups was not statistically significant, and we found no correlation with the development of neovascularization for any of the groups.

Aside from its retrospective nature, the main limitations of our study are related to multimodal retinal imaging. Baseline FAF and infrared images were not available, and although grading of CFP can reliably evaluate drusen characteristics and pigmentary changes, this method lacks sensitivity in the determination of GA and RPD. We do believe, however, that these limitations have a minor impact in our results.

In conclusion, by using an innovative, meticulous, and easily reproducible grading methodology, we found that the total number and area of drusen are 
significantly smaller in fellow eyes of RAP and that a total area of soft drusen $(\geq 125 \mu \mathrm{m})>510,196 \mu \mathrm{m}^{2}$ in the central $6,000 \mu \mathrm{m}$ is strongly associated with the development of neovascularization.

Key words: age-related macular degeneration, choroidal neovascularization, neovascular phenotypes, retina, retinal neovascularization, retinal angiomatous proliferation, type 3 neovascularization.

\section{References}

1. Hartnett ME, Weiter JJ, Garsd A, Jalkh AE. Classification of retinal pigment epithelial detachments associated with drusen. Graefes Arch Clin Exp Ophthalmol 1992;230:11-19.

2. Yannuzzi LA, Negrao S, Iida T, et al. Retinal angiomatous proliferation in age-related macular degeneration. Retina 2001;21:416-434.

3. Viola F, Massacesi A, Orzalesi N, et al. Retinal angiomatous proliferation: natural history and progression of visual loss. Retina 2009;29:732-739.

4. Matsumoto H, Sato T, Kishi S. Tomographic features of intraretinal neovascularization in retinal angiomatous proliferation. Retina 2010;30:425-430.

5. Yannuzzi LA, Freund KB, Takahashi BS. Review of retinal angiomatous proliferation or type 3 neovascularization. Retina 2008;28:375-384.

6. Freund KB, Ho IV, Barbazetto IA, et al. Type 3 neovascularization: the expanded spectrum of retinal angiomatous proliferation. Retina 2008;28:201-211.

7. Maruko I, Iida T, Saito M, et al. Clinical characteristics of exudative age-related macular degeneration in Japanese patients. Am Journal Ophthalmol 2007;144:15-22.

8. Fujimura S, Ueta $\mathrm{T}$, Takahashi $\mathrm{H}$, et al. Characteristics of fundus autofluorescence and drusen in the fellow eyes of Japanese patients with exudative age-related macular degeneration. Graefes Arch Clin Exp Ophthalmol 2013;251:1-9.

9. Gross NE, Aizman A, Brucker A, et al. Nature and risk of neovascularization in the fellow eye of patients with unilateral retinal angiomatous proliferation. Retina 2005;25:713-718.

10. Gharbiya M, Parisi F, Cruciani F, et al. Intravitreal antivascular endothelial growth factor for retinal angiomatous proliferation in treatment-naive eyes: long-term functional and anatomical results using a modified PrONTO-style regimen. Retina 2014;34:298-305.

11. Bressler NM. Photodynamic therapy of subfoveal choroidal neovascularization in age-related macular degeneration with verteporfin: two-year results of 2 randomized clinical trialstap report 2. Arch Ophthalmol 2001;119:198-207.

12. Rudnicka AR, Jarrar Z, Wormald R, et al. Age and gender variations in age-related macular degeneration prevalence in populations of European ancestry: a meta-analysis. Ophthalmology 2012;119:571-580.

13. Caramoy A, Ristau T, Lechanteur YT, et al. Environmental and genetic risk factors for retinal angiomatous proliferation. Acta Ophthalmol 2014;92:745-748.

14. Hayashi H, Yamashiro K, Gotoh N, et al. CFH and ARMS2 variations in age-related macular degeneration, polypoidal choroidal vasculopathy, and retinal angiomatous proliferation. Invest Ophthalmol Vis Sci 2010;51:5914-5919.

15. Campa C, Harding SP, Pearce IA, et al. Incidence of neovascularization in the fellow eye of patients with unilateral retinal angiomatous proliferation. Eye 2010;24:1585-1589.
16. Sawa M, Ueno C, Gomi F, Nishida K. Incidence and characteristics of neovascularization in fellow eyes of Japanese patients with unilateral retinal angiomatous proliferation. Retina 2014; 34:761-767.

17. Davis MD, Gangnon RE, Lee LY, et al. The age-related eye disease study severity scale for age-related macular degeneration: AREDS report No. 17. Arch Ophthalmol 2005;123: 1484-1498.

18. Friberg TR, Bilonick RA, Brennen P. Is drusen area really so important? An assessment of risk of conversion to neovascular AMD based on computerized measurements of drusen. Invest Ophthalmol Vis Sci 2012;53:1742-1751.

19. MPS. Five-year follow-up of fellow eyes of patients with agerelated macular degeneration and unilateral extrafoveal choroidal neovascularization. Macular Photocoagulation Study Group. Arch Ophthalmol 1993;111:1189-1199.

20. MPS. Risk factors for choroidal neovascularization in the second eye of patients with juxtafoveal or subfoveal choroidal neovascularization secondary to age-related macular degeneration. Macular Photocoagulation Study Group. Arch Ophthalmol 1997;115:741-747.

21. Marques JP, Costa M, Melo P, et al. Ocular risk factors for exudative AMD: a Novel Semiautomated grading system. ISRN Ophthalmol 2013;2013:464218.

22. Ferris FL, Davis MD, Clemons TE, et al. A simplified severity scale for age-related macular degeneration: AREDS Report No. 18. Arch Ophthalmol 2005;123:1570-1574.

23. Lim EH, Han JI, Kim CG, et al. Characteristic findings of optical coherence tomography in retinal angiomatous proliferation. Korean J Ophthalmol 2013;27:351-360.

24. Kim JH, Kim JR, Kang SW, et al. Thinner choroid and greater drusen extent in retinal angiomatous proliferation than in typical exudative age-related macular degeneration. Am J Ophthalmol 2013;155:743-749, 9 e1-2.

25. Monson DM, Smith JR, Klein ML, Wilson DJ. Clinicopathologic correlation of retinal angiomatous proliferation. Arch Ophthalmol 2008;126:1664-1668.

26. Shimada H, Kawamura A, Mori R, Yuzawa M. Clinicopathological findings of retinal angiomatous proliferation. Graefes Arch Clin Exp Ophthalmol 2007;245:295-300.

27. Kim JH, Lee TG, Kim JW, et al. Small retinal haemorrhages accompanied by macular soft drusen: prevalence, and funduscopic and angiographic characteristics. Br J Ophthalmol 2014; 98:1066-1072.

28. Silva R, Cachulo ML, Fonseca P, et al. Age-related macular degeneration and risk factors for the development of choroidal neovascularisation in the fellow eye: a 3-year follow-up study. Ophthalmologica 2011;226:110-118.

29. Silva RM, Cachulo ML, Figueira J, et al. Chorioretinal anastomosis and photodynamic therapy: a two-year follow-up study. Graefes Arch Clin Exp Ophthalmol 2007;245:1131-1139.

30. Silva RM, Faria de Abreu JR, Travassos A, Cunha-Vaz JG. Stabilization of visual acuity with photodynamic therapy in eyes with chorioretinal anastomoses. Graefes Arch Clin Exp Ophthalmol 2004;242:368-376.

31. Bird AC, Bressler NM, Bressler SB, et al. An international classification and grading system for age-related maculopathy and age-related macular degeneration. The International ARM Epidemiological Study Group. Surv Ophthalmol 1995;39: 367-374.

32. Friberg TR, Huang L, Palaiou M, Bremer R. Computerized detection and measurement of drusen in age-related macular degeneration. Ophthalmic Surg Lasers Imaging 2007;38: $126-134$. 
33. Sutter FK, Kurz-Levin MM, Fleischhauer J, et al. Macular atrophy after combined intravitreal triamcinolone acetonide (IVTA) and photodynamic therapy (PDT) for retinal angiomatous proliferation (RAP). Klin Monbl Augenheilkd 2006;223: $376-378$

34. Montero JA, Ruiz-Moreno JM, Sanabria MR, FernandezMunoz M. Efficacy of intravitreal and periocular triamcinolone associated with photodynamic therapy for treatment of retinal angiomatous proliferation. Br J Ophthalmol 2009;93:166-170.

35. McBain VA, Kumari R, Townend J, Lois N. Geographic atrophy in retinal angiomatous proliferation. Retina 2011;31: 1043-1052.

36. Yamazaki T, Koizumi H, Yamagishi T, Kinoshita S. Subfoveal choroidal thickness in retinal angiomatous proliferation. Retina 2014;34:1316-1322.

37. Hogg RE, Silva R, Staurenghi G, et al. Clinical characteristics of reticular pseudodrusen in the fellow eye of patients with unilateral neovascular age-related macular degeneration. Ophthalmology 2014;121:1748-1755.

38. Ueda-Arakawa N, Ooto S, Nakata I, et al. Prevalence and genomic association of reticular pseudodrusen in age-related macular degeneration. Am J Ophthalmol 2013;155:260-269 e2.

39. Cohen SY, Dubois L, Tadayoni R, et al. Prevalence of reticular pseudodrusen in age-related macular degeneration with newly diagnosed choroidal neovascularisation. $\mathrm{Br} \mathrm{J}$ Ophthalmol 2007;91:354-359.

40. Zweifel SA, Imamura Y, Spaide TC, et al. Prevalence and significance of subretinal drusenoid deposits (reticular pseudodrusen) in age-related macular degeneration. Ophthalmology 2010;117:1775-1781.

41. CAPT. Risk factors for choroidal neovascularization and geographic atrophy in the complications of age-related macular degeneration prevention trial. Ophthalmology 2008;115: 1474-1479, 9 e1-6. 